Article

\title{
Environmental Isolates of Multi-Azole-Resistant Aspergillus spp. in Southern Italy
}

\author{
Laura Trovato ${ }^{1,2, *(\mathbb{D}}$, Guido Scalia ${ }^{1,2}$, Maria Domina ${ }^{2}\left(\mathbb{D}\right.$ and Salvatore Oliveri ${ }^{1,2}$ \\ 1 U.O.C. Laboratory Analysis Unit, A.O.U. "Policlinico-Vittorio Emanuele”, 95123 Catania, Italy; \\ lido@unict.it (G.S.); oliveri@unict.it (S.O.) \\ 2 Department of Biomedical and Biotechnological Sciences, University of Catania, 95123 Catania, Italy; \\ m.domina@tiscali.it \\ * Correspondence: 1trovato@unict.it; Tel.: +39-0953781233
}

Received: 30 October 2018; Accepted: 4 December 2018; Published: 6 December 2018

\begin{abstract}
Azole resistance in Aspergillus spp. has been increasingly reported worldwide. Acquired azole resistance is probably linked to environmental exposure to fungicides used in agriculture. We collected a total of 84 soil and leaf samples from eight farms in Southern Italy. Aspergillus isolates were tested for resistance to itraconazole, posaconazole, and voriconazole by the EUCAST method. Five out of 84 samples yielded A. fumigatus isolates: four of them were itraconazole-resistant and were identified as $A$. fumigatus sensu stricto, three of them were posaconazole-resistant, and two were also voriconazole-resistant. All three isolates harbored the $\mathrm{TR}_{34} / \mathrm{L} 98 \mathrm{H}$ resistance mechanism, which was detected by DNA sequencing of the cyp51A gene. Fifteen out of 84 samples yielded Aspergillus spp. isolates and included 11 itraconazole-resistant isolates: Aspergillus section Nigri (9) and Aspergillus section Flavi (2). Our study reports for the first time the isolation of azole-resistant A. fumigatus harboring $\mathrm{TR}_{34} / \mathrm{L} 98 \mathrm{H}$ mutation from the environment of Southern Italy. The present work provides a better understanding of the magnitude of the environmental spread of azole resistance in the context of a necessary effective surveillance program to improve the management of Aspergillus-related disease.
\end{abstract}

Keywords: azole resistance; Aspergillus; environment

\section{Introduction}

Aspergillus spp. are ubiquitous saprophytic fungi that commonly occur in soil, water, and decaying vegetation, producing conidia which can be easily dispersed to the ambient air. Inhalation of such conidia, in association with certain risk conditions, can trigger aspergillosis, a group of several pulmonary diseases in humans, ranging from allergic bronchopulmonary aspergillosis (ABPA), chronic pulmonary aspergillosis (CPA), and aspergilloma to the most severe form, invasive aspergillosis (IA) [1,2]. Risk groups for aspergillosis mainly include immunocompromised subjects, such as patients with hematological malignancies, prolonged neutropenia or neutrophil disorders, pulmonary diseases, or solid-organ or hematopoietic stem cell transplantation [3-5]; those receiving prolonged high-dose corticosteroid therapy; and critically ill patients in intensive care units [6,7].

Triazole antifungal drugs (i.e., itraconazole, voriconazole, posaconazole, and isavuconazole) are the major compounds currently involved in the treatment and prophylaxis of aspergillosis [8]: itraconazole, the first orally active drug for aspergillosis, is commonly used in the treatment of chronic pulmonary aspergillosis and allergic conditions [9]; voriconazole, with its oral and intravenous availability, is the first-choice therapy for invasive aspergillosis [10]; posaconazole is preferred for the prevention of invasive aspergillosis in leukemia and bone marrow transplant patients [11]; and isavuconazole has only recently been approved for the treatment of invasive aspergillosis [12]. 
In recent years, the global emergence of azole-resistant isolates of Aspergillus spp. has been increasingly reported in patients under long-term antifungal treatment. However, azole-resistant isolates are also now being reported in azole-naïve patients with no known prior exposure to azole drugs, as well as in isolates from the environment [13]. The main resistance mechanism of the environmental isolates consists of a 34-base pair tandem repeat in the promoter region of the cyp51A gene, encoding the enzyme target of antifungal azoles and responsible for converting lanosterol to ergosterol via demethylation, in combination with a point mutation of the same gene leading to a substitution of leucine for histidine at codon $98\left(\mathrm{TR}_{34} / \mathrm{L} 98 \mathrm{H}\right)$ [14]. Strong evidence supports the environmental origin of resistant Aspergillus fumigatus to medical triazoles following exposure to triazole fungicides used in agriculture (the so-called DMI, or demethylation inhibitor fungicides) [15-18]. In particular, the isolation of azole-resistant isolates of Aspergillus in azole-naïve patients with invasive aspergillosis as well as breakthrough aspergillosis in patients on azole prophylaxis would support the hypothesis of the acquisition of strains with dominant resistance mechanisms from the environment. Few data are available on A. fumigatus azole resistance in Italy $[19,20]$, while azole resistance in non-fumigatus Aspergillus species has never been investigated. With the present study we aim to expand knowledge about the spread of environmental of $\mathrm{TR}_{34} / \mathrm{L} 98 \mathrm{H}$ mutation in Italy with data from southern regions. We also report data on the prevalence of phenotypic azole resistance in non-fumigatus Aspergillus spp. isolated from the environment in Southern Italy.

\section{Materials and Methods}

\subsection{Selection of Agricultural Areas and Enviromental Sampling}

After a careful search of the agricultural zones with the largest production of greenhouse and open-field vegetables and use of triazole fungicides, we selected five farms in Sicily (two farms producing vegetables, two producing citrus fruits and cereals, and one producing cereals), two farms producing vegetables and cereals in Calabria, and one farm producing olive trees and cereals in Basilicata. These companies were located at a distance of 5-10 km from urban centers. Bromuconazole, cyproconazole, paclobutrazol, difenoconazole, hexaconazole, fenbuconazole, tetraconazole, tebuconazole, tricyclazole, and penconazole were used as azole fungicides in the selected areas according to a rotational method, in order to avoid the emergence of specific resistance to any active ingredient. A total of 84 soil and leaf samples were examined: 20 samples from vegetable and cereal fields, 24 samples from citrus groves and vegetable fields, 23 samples from vegetable fields, 10 samples from cereal fields, and seven samples from olive groves and cereal fields. All samples were collected in the period between March and October 2015.

\subsection{Sample Treatment and Isolate Identification}

All samples were treated according to the method described by Snelders et al. [17] with minor modifications. Briefly, $2 \mathrm{~g}$ of soil and pulverized leaves of each sample were suspended in $8 \mathrm{~mL}$ of $0.2 \mathrm{M} \mathrm{NaCl}$ solution with $1 \%$ Tween 20 (Sigma, St. Louis, USA) and vortexed. The suspension was maintained at room temperature for 30 minutes and $100 \mu \mathrm{L}$ of supernatant was then inoculated on two plates of home-made Sabouraud dextrose agar (SDA, Biolife, Milan, Italy) supplemented with chloramphenicol (0.5 g/L, Sigma, Italy) and itraconazole (4 mg/L, Sigma, St. Louis, USA). Plates were then incubated at $32{ }^{\circ} \mathrm{C}$ and examined after 24,48 , and 72 hours of incubation.

All isolates were identified by standard phenotypic methods, based on the macroscopic and microscopic morphological study of Czapek agar medium colonies (Difco, Becton Dickinson, Buccinasco, Italy). Only the itraconazole-resistant Aspergillus section Fumigati isolates were identified by sequencing. In particular, for the identification of Aspergillus fumigatus sensu stricto, a portion of the $\beta$-tubulin gene was amplified using the primer set Tub5 (5'-TGACCCAGCAGATGTT-3') and Tub6 (5'-GTTGTTGGGAATCCACTC-3') and analyzed by Sanger sequencing as described elsewhere [21]. The identification was confirmed if a $99-100 \%$ sequence identity was detected when the obtained 
sequences were compared, by using Basic Local Alignment Search tool (BLAST), to the sequences present in the GenBank database (www.ncbi.nlm.nih.gov).

\subsection{Susceptibility Testing}

The isolates grown on SDA supplemented with itraconazole were tested for antifungal susceptibility to itraconazole, voriconazole, and posaconazole by broth microdilution according to the European Committee on Antimicrobial Susceptibility Testing (EUCAST) method E:DEF 9.1 [22]. Minimum inhibitory concentration (MIC) values $>2 \mathrm{mg} / \mathrm{L}$ were used for defining resistance to itraconazole and voriconazole, while values $>0.25 \mathrm{mg} / \mathrm{L}$ were used for defining resistance to posaconazole, according to EUCAST breakpoints [23-25]. In the absence of clinical breakpoints, the isolates of Aspergillus spp. were considered resistant when the MIC values were higher than the epidemiological cutoff value [26]. All assays were performed in duplicate, and Aspergillus fumigatus ATCC 204305 was included in each test as a quality-control strain.

\subsection{Detection of Mutation in Cyp51A Gene}

All of the itraconazole-resistant Aspergillus section Fumigati isolates were subjected to cyp51A gene sequencing. Genomic DNA was extracted by using Dneasy plant tissue kit (Qiagen, Crawley, UK). The cyp51A coding region was amplified by PCR using the primer set P450-A1 (5'-ATGGTGCCGATGCTATGG-3) and Cyp51AR2 (5'-AGTGA ATAGAGGAGTGA ATCC-3') and sequenced as described in Prigitano et al. [19]. The cyp51A gene promoter was amplified and sequenced using the primers P-A7 and P-A5 as previously described in Mellado et al. [27]. Sequence alignment was performed using the ClustalW algorithm (www.ebi.aci.uk). The cyp51A sequence from A. fumigatus strain 237 (GenBank accession number: AF338659) was used as a wild type reference.

\section{Results}

Aspergillus spp. grew on SDA supplemented with itraconazole in 20 of 84 leaf and soil samples (20/84, 23.8\%). Aspergillus section Fumigati grew in five of 84 samples $(5 / 84,5.9 \%)$ and was not isolated in samples from the olive groves and cereal fields of Basilicata and from the citrus groves and vegetable fields of Sicily. No Aspergillus spp. were isolated from the sampled olive groves and cereal fields of Basilicata (Table 1).

Susceptibility testing performed by broth microdilution on the five Aspergillus section Fumigati isolates confirmed itraconazole resistance in four isolates $(4 / 84,4.7 \%)$ with a range of MIC values from 8 to $>16 \mathrm{mg} / \mathrm{L}$, while no resistance was confirmed for the fifth isolate (MIC $=0.125 \mathrm{mg} / \mathrm{L}$ ). These four isolates (S-15, C-63, C-68, and S-80) were all identified as A. fumigatus sensu stricto by amplification and sequencing of a fragment of the $\beta$-tubulin gene. Three of them (S-15, C-68, and S-80), $(3 / 84,3.6 \%)$, were posaconazole resistant (range of MICs: $0.5-2 \mathrm{mg} / \mathrm{L}$ ) and two (C-68 and S-80), (2/84), 2.4\%) were voriconazole resistant (range of MICs: $4-8 \mathrm{mg} / \mathrm{L}$ ). Sequence analysis of the cyp51A gene showed the t364a point mutation, which results in the $\mathrm{L} 98 \mathrm{H}$ substitution, combined with the 34-base pair tandem repeat in the promoter region, in S-15, C-68, and S-80 isolates, while no $\mathrm{TR}_{34} / \mathrm{L} 98 \mathrm{H}$ mutation in the cyp51A gene was found in the C-63 isolate (Table 2).

The Aspergillus spp. isolates grown on SDA containing itraconazole were morphologically identified as follows: nine isolates of Aspergillus section Nigri, three isolates of Aspergillus section Flavi, and one isolate of Aspergillus section Terrei. In 11 of the 15 Aspergillus spp. isolates, itraconazole resistance was confirmed by broth microdilution: according to the EUCAST method, all Aspergillus section Nigri isolates $(9 / 84,10.7 \%)$ were considered itraconazole-resistant, as they displayed MIC values (range of MICs: 8 to $>16 \mathrm{mg} / \mathrm{L}$ ) higher than the epidemiological cutoff value (4 mg/L); two Aspergillus section Flavi isolates (2/84, 2.4\%) were itraconazole-resistant (range of MICs: 4-8 mg/L), and one showed reduced susceptibility to itraconazole (MIC value $=2 \mathrm{mg} / \mathrm{L}$ ); and the Aspergillus section Terrei isolate showed reduced susceptibility to itraconazole (MIC value $=2 \mathrm{mg} / \mathrm{L}$ ). Only four Aspergillus section Nigri isolates exhibited MIC values for voriconazole higher than the epidemiological 
cutoff value ( $4 \mathrm{mg} / \mathrm{L}$ ) and could be considered as voriconazole-resistant. MIC values for posaconazole were as follows: $0.125-1 \mathrm{mg} / \mathrm{L}$ for Aspergillus section Nigri isolates; $0.06-0.125 \mathrm{mg} / \mathrm{L}$ for Aspergillus section Flavi isolates; and $0.125 \mathrm{mg} / \mathrm{L}$ for the Aspergillus section Terrei isolate (Table 3).

Table 1. Environmental origin of itraconazole-resistant Aspergillus spp. and Aspergillus section Fumigati isolates.

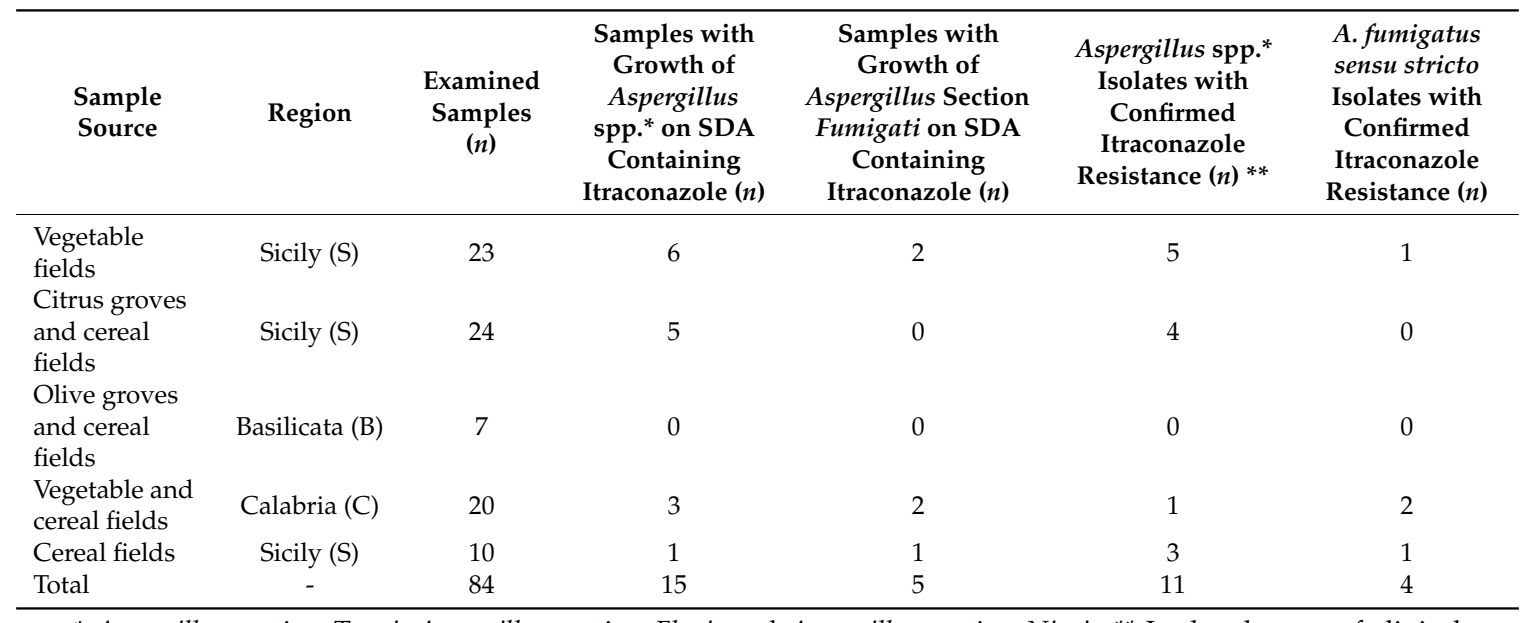

* Aspergillus section Terrei, Aspergillus section Flavi, and Aspergillus section Nigri. ${ }^{* *}$ In the absence of clinical breakpoint, the isolates of Aspergillus spp. were considered itraconazole resistant when the minimum inhibitory concentration (MIC) values were higher than the epidemiological cutoff value.

Table 2. Results of susceptibility testing performed by broth microdilution (EUCAST) and analysis of cyp51A mutations for four azole-resistant $A$. fumigatus sensu stricto isolates.

\begin{tabular}{|c|c|c|c|c|c|c|}
\hline $\begin{array}{c}\text { Isolate } \\
\text { Number }\end{array}$ & Fungicides Used & Sample Source & $\begin{array}{l}\text { MIC }(\mathrm{mg} / \mathrm{L} \\
\text { Itraconazole }\end{array}$ & $\begin{array}{l}\text { Determined } b \\
\text { Posaconazole }\end{array}$ & $\begin{array}{l}\text { EUCAST } \\
\text { Voriconazole }\end{array}$ & $\begin{array}{c}\text { Detection of } \\
\text { Cyp51A Mutations }\end{array}$ \\
\hline S-15 & $\begin{array}{l}\text { Bromuconazole } \\
\text { Tetraconazole } \\
\text { Penconazole }\end{array}$ & Vegetable field & $>16$ & 2 & 1 & $\mathrm{TR}_{34} / \mathrm{L} 98 \mathrm{H}$ \\
\hline$C-63$ & $\begin{array}{l}\text { Bromuconazole } \\
\text { Difenoconazole } \\
\text { Hexaconazole }\end{array}$ & $\begin{array}{l}\text { Vegetable and } \\
\text { cereal fields }\end{array}$ & 8 & 0.25 & 0.5 & None \\
\hline$C-68$ & $\begin{array}{l}\text { Bromuconazole } \\
\text { Difenoconazole } \\
\text { Hexaconazole }\end{array}$ & $\begin{array}{l}\text { Vegetable and } \\
\text { cereal fields }\end{array}$ & $>16$ & 0.5 & 4 & $\mathrm{TR}_{34} / \mathrm{L} 98 \mathrm{H}$ \\
\hline S-80 & $\begin{array}{l}\text { Bromuconazole } \\
\text { Cyproconazole } \\
\text { Fenbuconazole }\end{array}$ & Cereal field & $>16$ & 2 & 8 & $\mathrm{TR}_{34} / \mathrm{L} 98 \mathrm{H}$ \\
\hline
\end{tabular}

Itraconazole clinical breakpoint $\mathrm{S} \leq 1$ and $\mathrm{R}>2 \mathrm{mg} / \mathrm{L}$; posaconazole clinical breakpoint $\mathrm{S} \leq 0.125$ and $\mathrm{R}>0.25$ $\mathrm{mg} / \mathrm{L}$; voriconazole clinical breakpoint $\mathrm{S} \leq 1$ and $\mathrm{R}>2 \mathrm{mg} / \mathrm{L}$. 
Table 3. Results of EUCAST (European Committee on Antimicrobial Susceptibility Testing) susceptibility testing for 13 Aspergillus spp. isolates.

\begin{tabular}{|c|c|c|c|c|c|}
\hline \multirow{2}{*}{$\begin{array}{l}\text { Identified } \\
\text { Isolate }\end{array}$} & \multirow{2}{*}{$\begin{array}{l}\text { Isolate } \\
\text { Number }\end{array}$} & \multirow{2}{*}{ Sample Source } & \multicolumn{3}{|c|}{ MIC (mg/L) Determined by EUCAST } \\
\hline & & & Itraconazole & Posaconazole & Voriconazole \\
\hline \multirow{9}{*}{$\begin{array}{l}\text { Aspergillus } \\
\text { section Nigri }\end{array}$} & S-2 & Vegetable fields & 8 & 0.25 & 2 \\
\hline & S-7 & Vegetable fields & 8 & 0.25 & 1 \\
\hline & S-11 & Vegetable fields & $>16$ & 0.5 & 4 \\
\hline & S-19 & Vegetable fields & $>16$ & 0.5 & 4 \\
\hline & S-25 & $\begin{array}{l}\text { Citrus groves and } \\
\text { vegetable fields }\end{array}$ & 8 & 0.125 & 1 \\
\hline & S-31 & $\begin{array}{l}\text { Citrus groves and } \\
\text { vegetable fields }\end{array}$ & 8 & 0.125 & 2 \\
\hline & S-40 & $\begin{array}{l}\text { Citrus groves and } \\
\text { vegetable fields }\end{array}$ & 8 & 0.125 & 1 \\
\hline & S-75 & Cereal fields & $>16$ & 0.25 & 4 \\
\hline & S-77 & Cereal fields & $>16$ & 1 & 4 \\
\hline \multirow{3}{*}{$\begin{array}{l}\text { Aspergillus } \\
\text { section Flavi }\end{array}$} & S-3 & Vegetable fields & 4 & 0.06 & 0.5 \\
\hline & S-29 & $\begin{array}{l}\text { Citrus groves and } \\
\text { vegetable fields }\end{array}$ & 2 & 0.06 & 0.25 \\
\hline & $C-58$ & $\begin{array}{l}\text { Vegetable and } \\
\text { cereal fields }\end{array}$ & 8 & 0.125 & 0.5 \\
\hline $\begin{array}{l}\text { Aspergillus } \\
\text { section Terrei }\end{array}$ & S-81 & Cereal fields & 2 & 0.125 & 0.5 \\
\hline
\end{tabular}

Itraconazole/A. flavus clinical breakpoint $\mathrm{S} \leq 1$ and $\mathrm{R}>2 \mathrm{mg} / \mathrm{L}$; itraconazole/A. terreus clinical breakpoint $\mathrm{S} \leq 1$ and $\mathrm{R}>2 \mathrm{mg} / \mathrm{L}$; itraconazole/A. niger epidemiological cutoff value (ECOFF): $4 \mathrm{mg} / \mathrm{L}$; posaconazole/A. terreus clinical breakpoint $\mathrm{S} \leq 0.125$ and $\mathrm{R}>0.25 \mathrm{mg} / \mathrm{L}$; posaconazole/A. flavus and A. niger no clinical breakpoint or ECOFF; voriconazole/A. niger ECOFF: $2 \mathrm{mg} / \mathrm{L}$; voriconazole/A. flavus ECOFF: $2 \mathrm{mg} / \mathrm{L}$; voriconazole/A. terreus ECOFF: $2 \mathrm{mg} / \mathrm{L}$.

\section{Discussion}

The azole resistance of Aspergillus spp. is an increasing global health concern, and is most frequently observed in European countries [16,17,28,29]. Two routes of resistance development are generally described: long-term azole patient therapy in clinical settings, and following the application of azole compounds in agriculture. The environmental usage of triazole in agriculture has been suggested as playing an essential role in the development and spread of resistance to medical triazole in Aspergillus species [15,30]. Azole cross-resistance is also a growing concern. Several studies, for example, have demonstrated that isavuconazole highly correlates with voriconazole for A. fumigatus, while the eventual cross-resistance pattern is not well known for other Aspergillus species [31,32].

In the present study, we evaluated the prevalence of resistance to triazoles in Aspergillus spp. and Aspergillus section Fumigati strains isolated from agricultural areas in Southern Italy. We identified four azole-resistant $A$. fumigatus sensu stricto isolates, and three of them carried the $\mathrm{TR}_{34} / \mathrm{L} 98 \mathrm{H}$ resistance mechanism. Although $\mathrm{TR}_{34} / \mathrm{L} 98 \mathrm{H}$ represents the predominant mutation in azole-resistant $A$. fumigatus strains, several resistance mechanisms have been described [28,31], so the recovery of an isolate with an azole-resistant phenotype but no mutations in the cyp $51 \mathrm{~A}$ gene is not surprising. The isolation of A. fumigatus strains harboring the sole $\mathrm{TR}_{34} / \mathrm{L} 98 \mathrm{H}$ resistance mechanism could also be attributable to the use, for the initial screening, of only itraconazole-containing agar. This could result in the eventual exclusion of voriconazole-resistant strains that are not necessarily itraconazole resistant, since other azole resistance mechanisms could be involved (e.g., $\left.\mathrm{TR}_{46} / \mathrm{Y} 121 \mathrm{~F} / \mathrm{T} 289 \mathrm{~A}\right)[30,33]$. In future studies, the use of itraconazole- and voriconazole-containing plates could probably help to widen the range of azole-resistant isolates to obtain further and more detailed information. In our findings, in $4.7 \%$ $(4 / 84)$ of the samples, azole-resistant $A$. fumigatus sensu stricto isolates were found, $4.7 \%(4 / 84)$ were itraconazole-resistant, 3.6\% (3/84) were posaconazole-resistant, and $2.4 \%(2 / 84)$ were voriconazole resistant. Looking at the occurrence of azole-resistant $A$. fumigatus isolates across Europe, in the 
present study we found lower frequencies of resistant isolates compared to Italy $(16.9 \%$ for A. fumigatus sensu stricto) [20] and other European countries such as Denmark ( $8 \%$ for A. fumigatus) [18] and the Netherlands (20.4\% for A. fumigatus) [17]. These observations could probably be related to the isolation, in the environment of the sampled areas of Southern Italy, of a large number of non-fumigatus Aspergillus spp. (Aspergillus section Nigri, Aspergillus section Flavi, and Aspergillus section Terrei), which were itraconazole resistant: we found in particular $13.1 \%$ (11/84) itraconazole-resistant isolates, $2.4 \%(2 / 84)$ isolates with reduced susceptibility to itraconazole, and $4.76 \%(4 / 84)$ voriconazole-resistant isolates. Moreover, these observations could also depend on the fact that the study was designed to screen for resistant Aspergillus and consequently lacked the total number of Aspergillus isolates recovered (resistant and sensitive isolates). In conclusion, this study provides evidence for a high prevalence of phenotypic azole resistance in non-fumigatus Aspergillus spp. isolated from the environment in several areas of Southern Italy. These observations might be very useful to study the possible mechanisms underlying azole resistance in these other Aspergillus species which, although less pathogenic than A. fumigatus, are very frequently isolated in many areas of Southern Italy and in particular in Sicily, representing a potential cause of invasive disease in patients exposed to conidia from the environment.

In future studies, a surveillance program is needed to monitor the emergence of environmental multi-azole resistance, which could have important implications for the management of patients with Aspergillus diseases. Since early diagnosis and effective treatment of azole-resistant aspergillosis still represent a challenge, monitoring both clinical and environmental isolates would significantly contribute to a better understanding of the epidemiology and origin of azole-resistant Aspergillus spp. in the context of an inevitable battle against this global health problem.

Author Contributions: Design: Laura Trovato; Drafting of the manuscript: Laura Trovato and Maria Domina; Investigation: Laura Trovato and Salvatore Oliveri; Critical revisions of the manuscript: Salvatore Oliveri and Guido Scalia. All authors have read and approved the final manuscript.

Funding: This research received no external funding.

Acknowledgments: The work has been supported by Fellowship Program, Gilead.

Conflicts of Interest: The authors declare no conflict of interest.

\section{References}

1. Gonçalves, S.S. Global Aspects of Triazole Resistance in Aspergillus fumigatus with Focus on Latin American Countries. J. Fungi. 2017, 3, 5. [CrossRef] [PubMed]

2. Rivero-Menendez, O.; Alastruey-Izquierdo, A.; Mellado, E.; Cuenca-Estrella, M. Triazole Resistance in Aspergillus spp.: A Worldwide Problem? J. Fungi. 2016, 2, 21. [CrossRef] [PubMed]

3. Pagano, L.; Caira, M.; Candoni, A.; Offidani, M.; Martino, B.; Specchia, G.; Pastore, D.; Stanzani, M.; Cattaneo, C.; Fanci, R.; et al. Invasive aspergillosis in patients with acute myeloid leukemia: A SEIFEM-2008 registry study. Haematologica. 2010, 95, 644-650. [CrossRef]

4. Lanternier, F.; Cypowyj, S.; Picard, C.; Bustamante, J.; Lortholary, O.; Casanova, J.L.; Puel, A. Primary immunodeficiencies underlying fungal infections. Curr. Opin. Pediatr. 2013, 25, 736-747. [CrossRef]

5. Antachopoulos, C.; Walsh, T.J.; Roilides, E. Fungal infections in primary immunodeficiencies. Eur. J. Pediatr. 2007, 166, 1099-1117. [CrossRef] [PubMed]

6. Meersseman, W.; Vandecasteele, S.J.; Wilmer, A.; Verbeken, E.; Peetermans, W.E.; Van Wijngaerden, E. Invasive aspergillosis in critically ill patients without malignancy. Am. J. Respir Crit. Care Med. 2004, 170, 621-625. [CrossRef]

7. Vandewoude, K.; Blot, S.; Benoit, D.; Depuydt, P.; Vogelaers, D.; Colardyn, F. Invasive aspergillosis in critically ill patients: Analysis of risk factors for acquisition and mortality. Acta Clin Belg. 2004, 59, 251-257. [CrossRef]

8. Hagiwara, D.; Watanabe, A.; Kamei, K.; Goldman, G.H. Epidemiological and Genomic Landscape of Azole Resistance Mechanisms in Aspergillus Fungi. Front. Microbiol. 2016, 7, 1382. [CrossRef] 
9. Agarwal, R.; Vishwanath, G.; Aggarwal, A.N.; Garg, M.; Gupta, D.; Chakrabarti, A. Itraconazole in chronic cavitary pulmonary aspergillosis: A randomised controlled trial and systematic review of literature. Mycoses 2013, 56, 559-570. [CrossRef]

10. Walsh, T.J.; Anaissie, E.J.; Denning, D.W.; Herbrecht, R.; Kontoyiannis, D.P.; Marr, K.A.; Morrison, V.A.; Segal, B.H.; Steinbach, W.J.; Stevens, D.A.; et al. Treatment of aspergillosis: Clinical practice guidelines of the Infectious Diseases Society of America. Clin Infect. Dis. 2008, 46, 327-360. [CrossRef]

11. Farowski, F.; Vehreschild, J.J.; Cornely, O.A. Posaconazole: A next-generation triazole antifungal. Future Microbiol. 2007, 2, 231-243. [CrossRef]

12. Maertens, J.A.; Raad, I.I.; Marr, K.A.; Patterson, T.F.; Kontoyiannis, D.P.; Cornely, O.A.; Bow, E.J.; Rahav, G.; Neofytos, D.; Aoun, M.; et al. Isavuconazole versus voriconazole for primary treatment of invasive mould disease caused by Aspergillus and other filamentous fungi (SECURE): A phase 3, randomised-controlled, non-inferiority trial. Lancet. 2016, 387, 760-769. [CrossRef]

13. Howard, S.J.; Cerar, D.; Anderson, M.J.; Albarrag, A.; Fisher, M.C.; Pasqualotto, A.C.; Laverdiere, M.; Arendrup, M.C.; Perlin, D.S.; Denning, D.W. Frequency and evolution of Azole resistance in Aspergillus fumigatus associated with treatment failure. Emerg. Infect. Dis. 2009, 15, 1068-1076. [CrossRef] [PubMed]

14. Verweij, P.E.; Snelders, E.; Kema, G.H.; Mellado, E.; Melchers, W.J. Azole resistance in Aspergillus fumigatus: A side-effect of environmental fungicide use? Lancet Infect. Dis. 2009, 9, 789-795. [CrossRef]

15. Berger, S.; El Chazli, Y.; Babu, A.F.; Coste, A.T. Azole Resistance in Aspergillus fumigatus: A Consequence of Antifungal Use in Agriculture? Front. Microbiol. 2017, 8, 1024. [CrossRef] [PubMed]

16. Bromley, M.J.; van Muijlwijk, G.; Fraczek, M.G.; Robson, G.; Verweij, P.E.; Denning, D.W.; Bowyer, P. Occurrence of azole-resistant species of Aspergillus in the UK environment. J. Glob. Antimicrob Resist. 2014, 2, 276-279. [CrossRef] [PubMed]

17. Snelders, E.; Huis In 't Veld, R.A.; Rijs, A.J.; Kema, G.H.; Melchers, W.J.; Verweij, P.E. Possible environmental origin of resistance of Aspergillus fumigatus to medical triazoles. Appl Environ. Microbiol. 2009, 75, 4053-4057. [CrossRef] [PubMed]

18. Mortensen, K.L.; Mellado, E.; Lass-Flörl, C.; Rodriguez-Tudela, J.L.; Johansen, H.K.; Arendrup, M.C. Environmental study of azole-resistant Aspergillus fumigatus and other aspergilla in Austria, Denmark, and Spain. Antimicrob. Agents Chemother. 2010, 54, 4545-4549. [CrossRef] [PubMed]

19. Prigitano, A.; Venier, V.; Cogliati, M.; De Lorenzis, G.; Esposto, M.C.; Tortorano, A.M. Azole-resistant Aspergillus fumigatus in the environment of northern Italy, May 2011 to June2012. Euro Surveill. 2014, 19, 20747. [CrossRef] [PubMed]

20. Prigitano, A.; Esposto, M.C.; Romanò, L.; Auxilia, F.; Tortorano, A.M. Azole-resistant Aspergillus fumigatus in the Italian environment. J. Glob. Antimicrob Resist. 2018. [CrossRef]

21. Mellado, E.; Garcia-Effron, G.; Alcazar-Fuoli, L.; Melchers, W.J.G.; Verweij, P.E.; Cuenca-Estrella, M.; Rodriguez-Tudela, J.L. A new Aspergillus fumigatus resistance mechanism conferring in vitro cross-resistance to azole antifungals involves a combination of cyp51A alterations. Antimicrob. Agents Chemother. 2007, 51, 1897-1904. [CrossRef]

22. Rodriquez-Tudela, J.L.; Donnelly, J.P.; Arendrup, M.C.; Arikan, S.; Barchiesi, F.; Bille, J.; Chryssanthou, E.; Cuenca-Estrella, M.; Dannaoui, E.; Denning, D.; et al. EUCAST Technical Note on the method for the determination of broth dilution minimum inhibitory concentrations of antifungal agents for conidia-forming moulds. Clin. Microbiol. Infect. 2008, 14, 982-984.

23. Arendrup, M.C.; Cuenca-Estrella, M.; Lass-Flörl, C.; Hope, W.W.; European Committee on Antimicrobial Susceptibility Testing Subcommittee on Antifungal Susceptibility Testing (EUCAST-AFST). EUCAST technical note on Aspergillus and amphotericin B.; itraconazole, and posaconazole. Clin. Microbiol. Infect. 2012, 18, E248-E250. [CrossRef]

24. Verweij, P.E.; Howard, S.J.; Melchers, W.J.; Denning, D.W. Azole-resistance in Aspergillus: Proposed nomenclature and breakpoints. Drug Resist. Updat. 2009, 12, 141-147. [CrossRef]

25. Hope, W.W.; Cuenca-Estrella, M.; Lass-Flörl, C.; Arendrup, M.C.; European Committee on Antimicrobial Susceptibility Testing-Subcommittee on Antifungal Susceptibility Testing (EUCAST-AFST). EUCAST technical note on voriconazole and Aspergillus spp. Clin. Microbiol. Infect. 2013, 19, E278-E280. [CrossRef] 
26. Pfaller, M.; Boyken, L.; Hollis, R.; Kroeger, J.; Messer, S.; Tendolkar, S.; Diekema, D. Use of epidemiological cutoff values to examine 9-year trends in susceptibility of Aspergillus species to the triazoles. J. Clin Microbiol. 2011, 49, 586-590. [CrossRef]

27. Mellado, E.; Diaz-Guerra, T.M.; Cuenca-Estrella, M.; Rodriguez-Tudela, J.L. Identification of two different 14-alpha sterol demethylase-related genes (cyp51A and cyp51B) in Aspergillus fumigatus and other Aspergillus species. J. Clin. Microbiol. 2001, 39, 2431-2438. [CrossRef]

28. European Centre for Disease Prevention and Control. Risk Assessment on the Impact of Environmental Usage of Triazoles on the Development and Spread of Resistance to Medical Triazoles in Aspergillus Species; ECDC: Stockholm, Sweden, 2013.

29. Snelders, E.; van der Lee, H.A.L.; Kuijpers, J.; Rijs, A.J.M.M.; Varga, J.; Samson, R.A.; Mellado, E.; Donders, A.R.T.; Melchers, W.J.G.; Verweij, P.E. Emergence of azole resistance in Aspergillus fumigatus and spread of a single resistance mechanism. PLoS Med. 2008, 5, e219. [CrossRef]

30. Verweij, P.E.; Chowdhary, A.; Melchers, W.J.; Meis, J.F. Azole Resistance in Aspergillus fumigatus: Can We Retain the Clinical Use of Mold-Active Antifungal Azoles? Clin. Infect. Dis. 2016, 62, 362-368. [CrossRef]

31. Chowdhary, A.; Sharma, C.; van den Boom, M.; Yntema, J.B.; Hagen, F.; Verweij, P.E. Multi-azole-resistant Aspergillus fumigatus in the environment in Tanzania. J. Antimicrob. Chemother. 2014, 69, 2979-2983. [CrossRef]

32. Gregson, L.; Goodwin, J.; Johnson, A.; McEntee, L.; Moore, C.B.; Richardson, M.; Hope, W.W.; Howard, S.J. In vitro susceptibility of Aspergillus fumigatus to isavuconazole: Correlation with itraconazole, voriconazole, and posaconazole. Antimicrob. Agents Chemother. 2013, 57, 5778-5780. [CrossRef]

33. Ren, J.; Jin, X.; Zhang, Q.; Zheng, Y.; Lin, D.; Yu, Y. Fungicides induced triazole-resistance in Aspergillus fumigatus associated with mutations of TR46/Y121F/T289A and its appearance in agricultural fields. J. Hazard. Mater. 2017, 326, 54-60. [CrossRef]

(C) 2018 by the authors. Licensee MDPI, Basel, Switzerland. This article is an open access article distributed under the terms and conditions of the Creative Commons Attribution (CC BY) license (http:/ / creativecommons.org/licenses/by/4.0/). 